\title{
CD96 as a Leukemic Stem Cell Marker in Acute Myeloid Leukemia Patients: Relation to Remission Induction Chemotherapy
}

\author{
MOHAMED A. FATEEN, M.D.*; RASHA RAWI, M.D.**; HEBA E. ABD EL-RAHMAN, M.Sc.*** and \\ SAHAR K. HUSSEIN, M.D.* \\ The Department of Clinical \& Chemical Pathology*, Clinical Hematology Unit, Internal Medicine Department**, \\ Faculty of Medicine, Cairo University and Clinical \& Chemical Pathology, Armed Forces Central Laboratory***
}

\begin{abstract}
Background: Leukemic stem cells (LSCs) play a crucial role in chemotherapy resistance in acute myeloid leukemia (AML), the classical LSCs phenotype is CD34+/CD38-. Successful eradication of LSCs requires combination of different strategies including targeting LSC specific surface molecules.

Aim of Study: To investigate the role of CD96, as a stem cell marker, in AML and its relation to induction therapy outcome.

Material and Methods: The current study was conducted on 50 patients with de-novo AML, in addition to 20 controls. Using multicolor flow cytometry, we analyzed the expression of CD96, a potential marker for LSCs among CD34+/CD38cell population in AML patients at initial diagnosis and correlate it to the response of induction therapy.

Results: Percentage of CD96 among CD34+/CD38- was significantly higher in AML patients compared to control group $(p<0.001)$. However, no statistical significant difference was observed between complete remission (CR) and nonremission (NCR) groups. Also the correlation studies of LSC markers with laboratory findings revealed no significant correlation.

Conclusions: CD96 expression among CD34+/CD38cells may be used as a useful marker for detection of LSCs in AML patients. However its expression is not correlated to post induction therapy outcome.
\end{abstract}

Key Words: Acute myeloid leukemia $(A M L)$ - Leukemic stem cell (LSC) - CD96 - Induction therapy.

\section{Introduction}

ACUTE myelogenous leukemia (AML) is a clonal, malignant disease of hematopoietic tissue that is recognized by excessive production of (leukemic) blast cells in the bone marrow (BM), and defective production of normal blood cells, hence causing anemia, neutropenia and thrombocytopenia [1].

Correspondence to: Dr. Mohamed A. Fateen, E-Mail: mo.fateen@kasralainy.edu.eg
Studies have shown that only a small subset of leukemic cells, the leukemia stem cells (LSCs), can proliferate extensively in vitro and in vivo, and have an essential role in the relapse and refractoriness of AML to treatment [2].

Although these cells represent a small and variable proportion of the totality of the AML cells (0.2-1\% depending on the patient), they were of particular importance in transferring AML from human patient to NOD/SCID mice and were referred as SCID leukemia-initiating cells (SL-IC). The LSC that initiate leukemia are almost always in the CD34+/38- fraction and never in the CD38+ fraction, and were identified prospectively and purified as [Thy1-, CD34+, CD38-] cells from various patients. Some methods such as multicolor flow cytometry and side-population assay are essential for identifying LSCs whether in peripheral blood or BM samples [3-5].

The role of several LSC-associated markers such as CD33, CD96, and Death associated protein kinase (DAPK) expression in AML and their relationship with prognosis is still under investigation [6].

About $30 \%$ of human AML samples express CD96 and because most of the normal hematopoietic stem cells are negative for CD96, it was suggested that CD96 could be a potential marker for targeted therapy [7].

The aim of this study is to assess the expression of CD96 among CD34+/CD38- cell population in AML patients at initial diagnosis and correlate it to the response of induction therapy. 


\section{Patients and Methods}

The study was conducted on 50 newly diagnosed de novo adult AML patients at time of initial diagnosis before induction of therapy. Patients were selected randomly from cases referred to the Clinical Hematology Unit and Medical Oncology Departments of Kasr Alainy Faculty of Medicine during the period from January 2019 till December 2019.

In addition, $20 \mathrm{BM}$ samples from patients with non-malignant hematological disorders: Idiopathic thrombocytopenic purpura, hypersplenism and some normal BM samples of donors within the bone marrow transplantation unit were included as a control group.

All patients included in the study were subjected to complete history taking and clinical examination for organomegally and/or anemic manifestations. Laboratory investigations including: Complete blood picture, BM examination, immunophenotyping (IPT) and cytochemistry to establish the FAB classification as well as cytogenetic studies. For all patients with AML, peripheral blood (PB), and $\mathrm{BM}$ aspirate samples were repeated at day 28 from the start of chemotherapy to assess complete remission (CR).

Flow cytometric detection of LSCs was performed using CD34, CD38, CD96 monoclonal antibodies for both groups.

\section{Flow cytometry analysis:}

BM samples were analyzed for enumeration of LSCs using multicolor flow cytometry (Cytomics FC500) from Beckman coulter. A logarithmic scale was implemented for forward scatter signal, side scatter signal and each fluorescent channel. Data analysis was performed as follows: For each specimen about 10,000 cells were analyzed, primary gate was constructed on CD34+CD38- cells and measuring CD96+ percent within the primary gate. Data was recorded as percentage and mean fluorescence intensity (MFI).

\section{Statistical analysis:}

Data was coded and entered using the statistical package SPSS (Statistical Package for the Social Sciences) version 15. Data was summarized using mean, standard deviation, median, minimum and maximum in quantitative data and using frequency (count) and relative frequency (percentage) for categorical data. Comparisons between quantitative variables were done using the non-parametric Kruskal-Wallis and Mann-Whitney tests, For comparing categorical data, Chi square $\left(\chi^{2}\right)$ test was performed. Correlations between quantitative variables were done using Spearman correlation coefficient. $p$-values less than 0.05 were considered as statistically significant.

\section{Results}

The current study was conducted on 50 patients with de novo AML, 32 males (64\%) and 18 females (36\%). Their ages ranged between 19 and 70 years (median: 40 years, mean \pm SD: $41.6 \pm 15.2$ years). Twenty age and sex matched participants presented with non-hematological malignancies as a control group, 11 males (55\%) and 9 females (45\%). Their ages ranged between 22 and 63 years, median: 39 years, mean \pm SD: $41.4 \pm 11.8$ years).

Among AML groups, 4 patients $(8.0 \%)$ were M0, 10 patients (20\%) were M1, 10 patients $(20 \%)$ were M2, 4 patients $(8.0 \%)$ were M3, 19 patients (38.0\%) were M4, and 3 patients were M5 (6.0\%).

Molecular testing for common translocations: Inversion 16 was positive in $1 / 50(2.0 \%)$, negative in $26 / 50(52.0 \%), \mathrm{t}(8 ; 21)$ was positive in $2 / 50$ (4.0\%), negative in 25/50 (50.0\%), FLT3-ITD was positive in $22 / 50(44.0 \%)$, negative in $10 / 50$ $(20.0 \%)$.

Karyotyping was successful for 30 patients. Twenty four had normal karyotype, three had hyperdiploidy, one had monosomy seven and two had hypodiploidy.

Table (1): Demonstrates the demographic features of patients and controls.

Table (2); Figs. (1,2): Show comparisons between cases and control in expression of CD34, CD38 and CD96 and they were statistically significant between the two groups $(p<0.001)$.

After induction therapy; $32 / 50(64 \%)$ patients achieved CR and 18/50 (36\%) patients did not achieve complete remission (NCR).

Table (3): Comparison between CR and NCR groups regarding CD34+/CD38- and CD34+/CD38/CD96+ revealed no statistically significant difference between the two groups.

Table (4): A cutoff value was estimated as a median value of LSCs percentage expression dividing AML patients to high expression and low expression groups. No statistical significance was observed among CR and NCR patients.

No significant correlations were found between LSCs markers CD34+/CD38-/CD96+ and labora- 
tory parameters: Hemoglobin, total leukocyte count, platelet count, initial blast cell count, and blasts cells on day 14 and day 28.

Regarding the clinical data, the percentage of [CD34+/CD38-/CD96+] cells in patients presenting with hepatomegaly, hepatosplenomegaly, splenomegaly (median: $41.20 \%$; range: $31.50-67.70 \%$; median: $82.1 \%$; range: $23.95-96.10$; median $74.30 \%$; range: $010.9-93.6 \%$ respectively) and lymphadenopathy (median: $73.75 \%$; range: 40.5 $97.2 \%$ ) showed no statistically significant difference from those free from hepatomegaly, hepatosplenomegaly, splenomegaly (median: $77.2 \%$; range: $24.0-99.4 \%$ ) or lymphadenopathy (median: $77.25 \%$; range: $10.9-99.4 \%)(p=0.295,0.746$ respectively).

Table (1): Demographic features of AML and control groups.

\begin{tabular}{|c|c|c|c|c|}
\hline & \multicolumn{2}{|c|}{$\begin{array}{l}\text { AML group } \\
\quad(n=50)\end{array}$} & \multicolumn{2}{|c|}{$\begin{array}{l}\text { Control group } \\
\quad(\mathrm{n}=20)\end{array}$} \\
\hline & Number & $\%$ & Number & $\%$ \\
\hline \multicolumn{5}{|l|}{ Gender: } \\
\hline Male & 32 & 64.0 & 11 & 55.0 \\
\hline Female & 18 & 36.0 & 9 & 45.0 \\
\hline \multicolumn{5}{|l|}{ Age (years): } \\
\hline Median & \multicolumn{2}{|c|}{40} & \multicolumn{2}{|c|}{41} \\
\hline Range & \multicolumn{2}{|c|}{ 19-70 } & \multicolumn{2}{|c|}{$22-63$} \\
\hline Mean $\pm S D$ & \multicolumn{2}{|c|}{$41.6 \pm 15.2$} & \multicolumn{2}{|c|}{$41.4 \pm 11.8$} \\
\hline
\end{tabular}

Table (2): Comparison between AML $(n=50)$ and control groups $(n=20)$ as regards MFI/percentage of CD34+/CD38-/CD96 +ve cells before treatment

\begin{tabular}{|c|c|c|c|c|c|}
\hline \multirow{3}{*}{ Markers data } & \multicolumn{4}{|c|}{ Groups } & \multirow{3}{*}{$\begin{array}{c}p- \\
\text { value }\end{array}$} \\
\hline & \multicolumn{2}{|c|}{ AML $(\mathrm{n}=50)$} & \multicolumn{2}{|c|}{ Control (n=20) } & \\
\hline & Median & Range & Median & Range & \\
\hline CD34+/CD3 8-\% & 4.35 & $0.10-51.70$ & 0.55 & $0.1-3.2$ & $<0.001$ \\
\hline CD34+/CD3 8-MFI & 0.81 & $0.46-1.93$ & 0.53 & $0.4-1.6$ & $<0.001$ \\
\hline $\begin{array}{l}\text { CD34+/CD3 8-/ } \\
\text { CD96+\% }\end{array}$ & 3.55 & $1.21-8.8$ & 2.11 & $1.01-3.75$ & $<0.001$ \\
\hline $\begin{array}{c}\text { CD34+/CD3 8-/ } \\
\text { CD96+ MFI }\end{array}$ & 3.68 & $0.05-31.6$ & 0.71 & $0.01-3.53$ & $<0.001$ \\
\hline
\end{tabular}

MFI: Mean fluorescence intensity.

Table (3): Comparison between CR and NCR groups.

\begin{tabular}{|c|c|c|c|c|c|}
\hline \multirow{3}{*}{ Markers } & \multicolumn{4}{|c|}{ CR /NCR groups } & \multirow{3}{*}{$\begin{array}{c}p- \\
\text { value }\end{array}$} \\
\hline & \multicolumn{2}{|c|}{$\mathrm{CR}(\mathrm{n}=32)$} & \multicolumn{2}{|c|}{ NCR $(n=18)$} & \\
\hline & Median & Range & Median & Range & \\
\hline CD34+/CD38- \% & 6.82 & $0.10-51.70$ & 2.58 & $0.10-40.90$ & 0.603 \\
\hline CD34+/38- MFI & 0.82 & $0.46-1.93$ & 0.78 & $0.46-1.60$ & 0.424 \\
\hline $\begin{array}{c}\text { CD34+/CD3 8-/ } \\
\text { CD96+ \% }\end{array}$ & 75.20 & $10.90-99.40$ & 77.25 & $31.50-97.20$ & 0.658 \\
\hline $\begin{array}{c}\text { CD34+/CD3 8-/ } \\
\text { CD96+ MFI }\end{array}$ & 2.40 & $0.96-4.35$ & 2.41 & $1.62-3.89$ & 0.768 \\
\hline
\end{tabular}

$p$-value $<0.05$ is statistically significant. MFI: Mean fluorescence intensity. \%: Percentage.
Table (4): Comparison between CR and NCR groups regarding CD34+/CD38- and CD34+/CD38-/CD96+ according to median.

\begin{tabular}{|c|c|c|c|c|c|c|c|c|}
\hline \multirow{2}{*}{$\begin{array}{l}\text { Median } \\
\text { marker } \\
\text { expression }\end{array}$} & \multirow{2}{*}{$\begin{array}{c}\text { Marker } \\
\text { expression }\end{array}$} & \multicolumn{2}{|c|}{$\mathrm{CR}$} & \multicolumn{2}{|c|}{ NCR } & \multicolumn{2}{|c|}{ Total } & \multirow{2}{*}{$\begin{array}{c}p- \\
\text { value }\end{array}$} \\
\hline & & Count & $\%$ & Count & $\%$ & Count & $\%$ & \\
\hline $\begin{array}{l}\text { CD34+/CD38- } \\
\%\end{array}$ & Low & 14 & 43.8 & 11 & 61.1 & 25 & 50.0 & 0.239 \\
\hline Median: 4.35 & High & 18 & 56.2 & 7 & 38.9 & 25 & 50.0 & \\
\hline $\begin{array}{c}\text { CD34+/CD38/ } \\
\text { CD96+\% }\end{array}$ & Low & 17 & 53.1 & 8 & 44.4 & 25 & 50.0 & 0.556 \\
\hline Median: 76.15 & High & 15 & 46.9 & 10 & 55.6 & 25 & 50.0 & \\
\hline
\end{tabular}

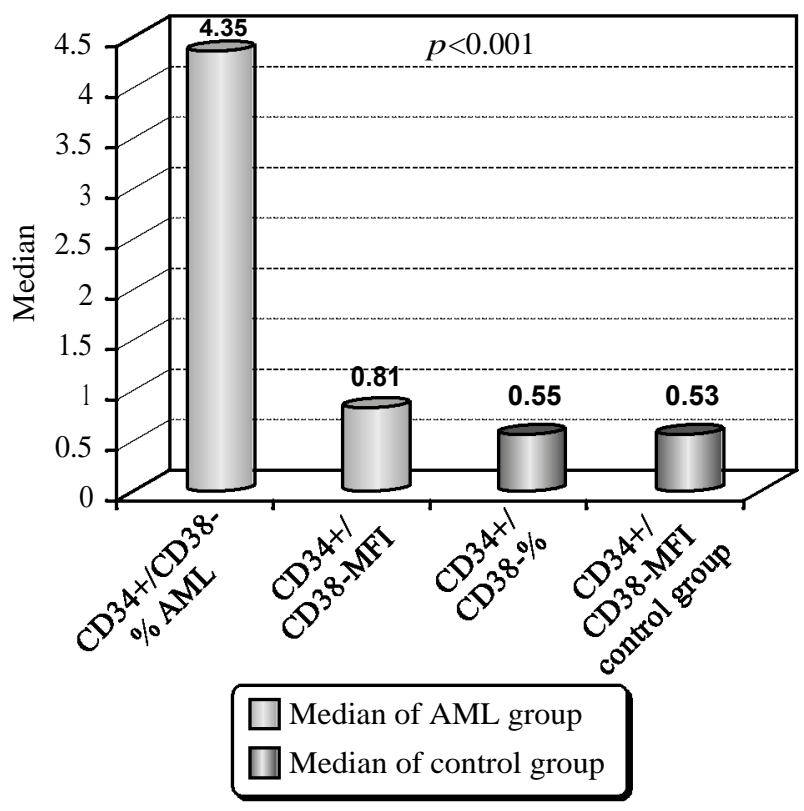

Fig. (1): Comparison between AML $(n=50)$ and control $(n=20)$ groups as regards percentage of [CD34+/CD38-] cell.

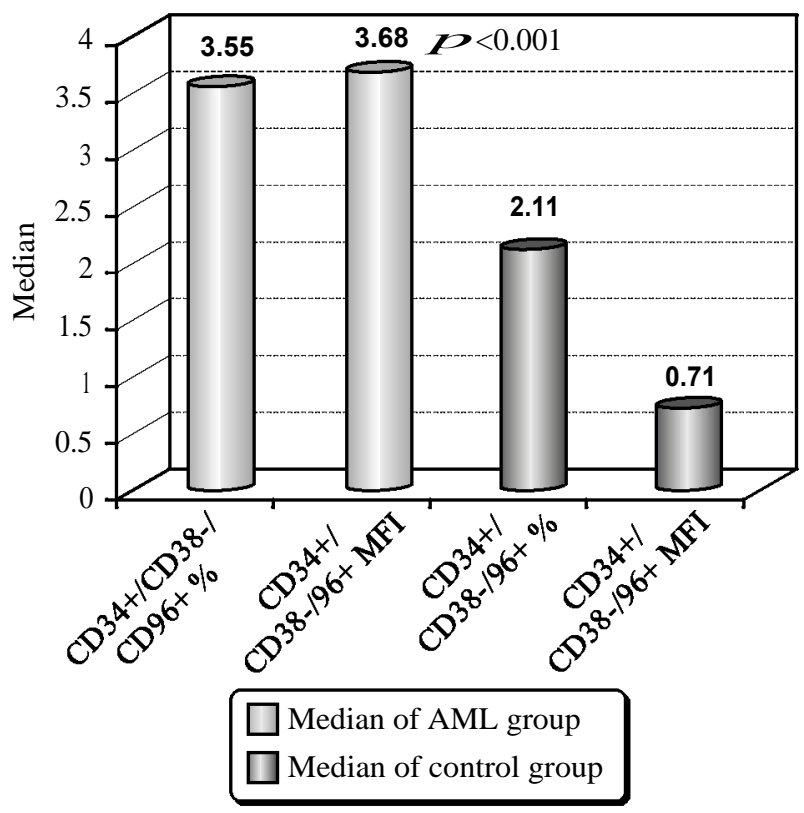

Fig. (2): Comparison between AML and control groups as regards MFI/Percentage of [CD34+/CD38-/CD96+] cells. 

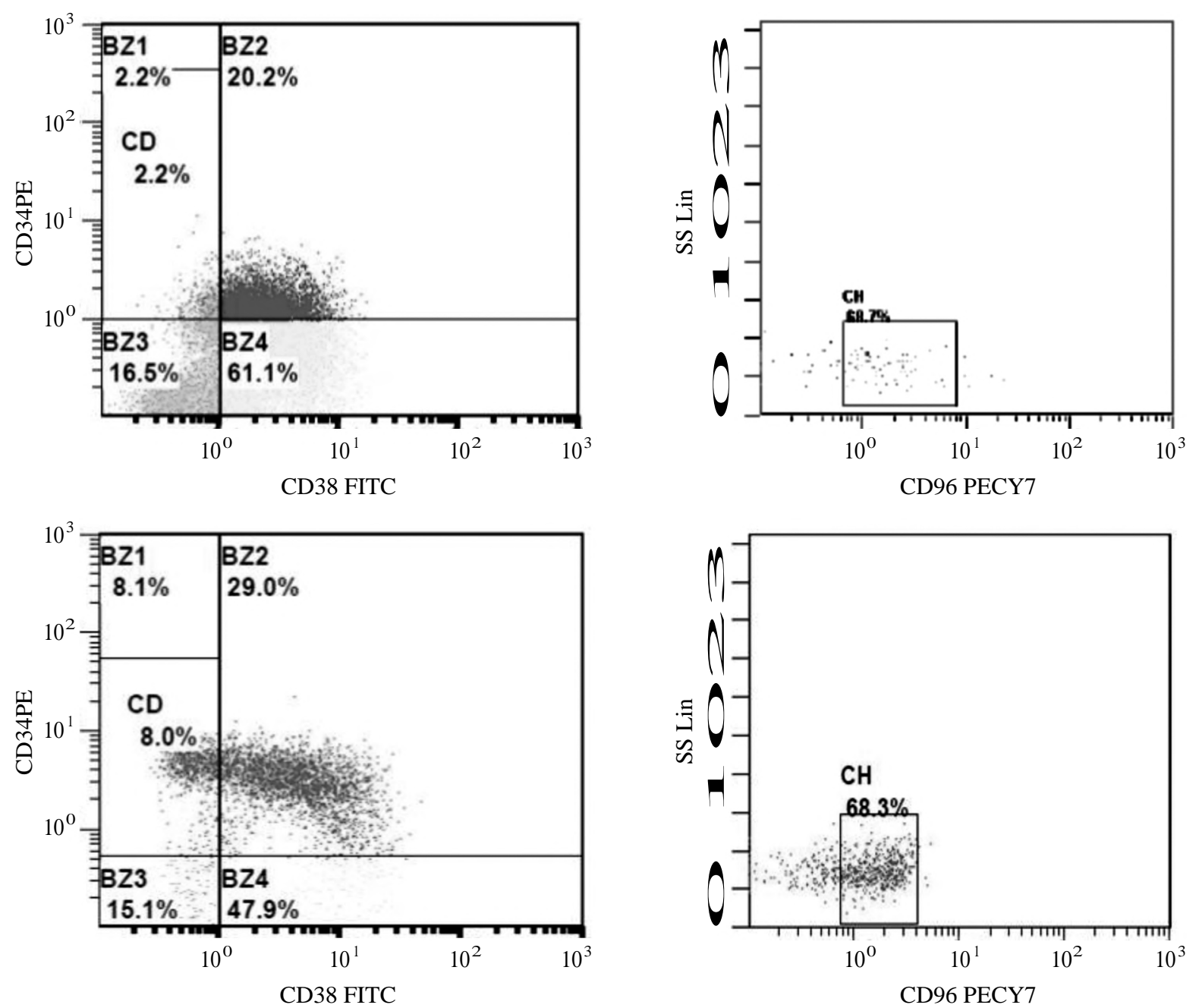

Fig. (3): Flow cytometric analysis of CD34+CD38-CD96+cells: Comparison of percentage/MFI of CD96+ cells among CD34+ CD38- cell population in a control (upper row) and an AML case (lower row).

\section{Discussion}

To study the expression of LSCs markers in AML and their association to induction chemotherapy, our results show that the percentage of CD34+/CD38- in the AML group at diagnosis was higher and statistically significant when compared to the control group, also the MFI of CD34+/CD38shows the same result, being higher and statistically significant. Results are concomitant to what were found by Du et al., as well as Mostafa et al., [8,9]

The expression of the cell surface antigen CD96, relevant to human hematopoiesis on the primitive cell population CD34+/CD38-, was analyzed and results show that CD96 percentage and MFI expression detected as a surface marker on AML at diagnosis is higher than the control group and is statistically significant.

The higher expression of CD96 among CD34+/ CD38- cell population in AML patients is consistent with several studies. Hosen et al., [7] found that CD96 could be detected on most of CD34+CD38AML stem cells, and its expression could be correlated with the function of LSCs. Only CD96+ LSCs can induce AML in NOD/SCID mice, suggesting that CD96 expression difference may affect the pathogenesis and prognosis of AML. Also, ChávezGonzález et al., [10] showed an increased frequency of CD96+ and CD123+ cells within the CD34+ cell population from pediatric AML patients at diagnosis compared to normal group. Further studies were done by Zhao M. et al. [11]; Du et al. [8] and Hussein et al. [12] showed consistent findings.

Regarding the prognostic impact of CD34 and CD38 separately, or CD34+/CD38- expression as LSC markers and their relationship with post induction therapy, the present study shows no statistical significance between their expression and the short-term AML prognosis. This result is similar to what was found by El Mostafa et al., [9]'s study. 
Other studies showed opposite results, Terwijin et al., [13] reported that the frequency of CD34+/ CD38- as putative LSCs compartment in AML patients at diagnosis have a strong prognostic impact and by multivariate analysis showed that CD34+/CD38- frequency after first and second treatment cycles was an independent prognostic factor for relapse free survival (RFS) and overall survival (OS), while the neoplastic part of the CD34+/CD38+ as a stem cell compartment has no prognostic impact at all.

Similarly, other studies regarding the prognostic impact of CD34+/CD38- LSCs on disease outcome were performed. The prognostic influence of the complete absence of CD34+/CD38- cells turned out to be an independent prognostic factor identifying patients with better prognosis in adult and pediatric AML patients, compared to patients with high or low CD34+/CD38- LSC frequencies Hanekamp et al., [5] and Zeijlemaker et al., [14]

When evaluating the relation between CD96 expressions separately or among CD34+/CD38population and the post induction therapy effect and prognosis, results show no statistical significance.

In contrast with the current study results, Hosen et al., [7] suggested that CD96 expression difference may affect the pathogenesis and prognosis of AML. Also, Majeet and Weissman [15]'s study revealed that antibodies targeting CD96 on LSCs exhibited curative effect on alleviating the disease and improving prognosis, suggesting the value of CD96 down regulation on AML targeted therapy.

While Zaho et al.'s [11] study concluded that both CD96 and CD123 were markers of LSCs, CD96 might be more specific, and patients with expression of LSC markers especially with the expression of CD96 had a lower rate of remission, shorter survival time and poor prognosis. Among 29 cases with CD96 expression, only 14 acquired CR or partial remission (PR) within two courses of chemotherapy. On the contrary, among 57 cases without CD96 expression, 41 acquired CR or PR. Results were statistically highly significant. A recent study by Mohammad $\mathrm{H}$ et al., indicated that CD96\% in patients with NCR was higher than those with CR ( $p=0.004)$ [16].

Du et al., [8] and Jiang et al., [6n] based their studies on the background theory to clarify the relationship between the expressions of certain surface markers such as: CD33, CD96, and DAPK in the prognosis of AML. Du et al., [8] reported that the CR rate in AML patients with CD96 expression of $<10 \%$ in CD34+CD38- LSC was markedly higher than in the patients with CD96 expression of $>10 \%$. The study done by Jiang et al., [6n] showed that after chemotherapy, the response rate in the CD33 and CD96 high expression groups was significantly lower than the groups with CD33 and CD96 low expression, suggesting CD33 and CD96 elevation may reduce the sensitivity to chemotherapy and may be related to poor prognosis.

Further analysis demonstrated that the one-year survival rate, three-year survival rate, and median survival time in the CD33 and CD96 high expression groups were obviously lower than that in the groups with low CD33 or CD96 expression. Regarding CD96, the response rate (CR + PR) in CD96 high expression group result were significantly lower than that of the CD96 low expression group [6n]

In this work, the expression of CD96 among CD34+/CD38- cells was evaluated against other clinical and hematological parameters such as gender, hemoglobin level, platelets, blast percentage, and results showed no significant correlation. A previous study performed on patients with MDS by Zhang et al., [17] revealed that the expression levels of CD96 were significantly correlated with the proportion of the BM blasts.

Also, regarding the expression of CD96 among CD34+/CD38- cells and the TLC, there was no significant correlation. This is contrary to Zhao et al., [11] who stated that CD96 expression level was higher with hyperleukocytosis, as well as AlFatlawi and Musa [18] who mentioned that the expression of CD96 was associated with increased TLC and BM blast cells at presentation.

Yabushita et al.'s [19] work using multiple LSCs markers (CD96, CD25 and CD123) revealed that multiple LSC marker expression was significantly associated with shorter three-year OS, compared with single or no LSC marker expression.

Work performed on the association between expression of LSCs gene and clinical outcomes in AML showed that high expression of a LSC gene expression signature is independently associated with adverse outcomes in AML [20].

The current study results concluded that the expression of CD34+/CD38- (percentage and MFI) in the AML group was higher and statistically significant when compared to the control group. Also, the expression of surface antigen CD96 
among CD34+/CD38- population (percentage and $\mathrm{MFI}$ ) was higher and statistically significant when compared to control group.

Regarding the prognostic impact of CD34+/ CD38- LSCs on disease outcome, results show no statistical significance between their expression and the short-term AML prognosis.

Similarly, the current study shows no statistical significance when evaluating the relation between CD96 expressions separately or among CD34+/ CD38- population on disease outcome after post induction therapy.

We concluded that CD96 expression among CD34 may be used as a useful marker for detection of LSCs in AML patients, however CD96 expression is not correlated to post induction therapy outcome.

\section{References}

1- VEDI A., SANTORO A., DUNANT C.F., DICK J.E. and LAURENTI E.: Molecular landscapes of human hematopoietic stem cells in health and leukemia. Ann. N. Y Acad. Sci. Apr., 1370 (1): 5-14. doi: 10.1111/nyas.12981. Epub 2015 Dec 11. PMID: 26663266, 2016.

2- STIEHL T., BARAN N., HO A.D. and MARCINIAKCZOCHRA A.: Cell division patterns in acute myeloid leukemia stem-like cells determine clinical course: A model to predict patient survival. Cancer Res. Mar., 15; 75 (6): 940-9. doi: 10.1158/0008-5472.CAN-14-2508. Epub 2015 Jan 22. PMID: 25614516, 2015.

3- MISAGHIAN N., LIGRESTI G., STEELMAN L.S., BERTRAND F.E., BÄSECKE J., LIBRA M., NICOLETTI F., STIVALA F., MILELLA M., TAFURI A., CERVELLO M., MARTELLI A.M. and McCUBREY J.A.: Targeting the leukemic stem cell: The Holy Grail of leukemia therapy. Leukemia. Jan., 23 (1): 25-42. doi: 10.1038/leu. 2008.246. Epub 2008 Sep 18. PMID: 18800146; PMCID: PMC2627788, 2009.

4- DICK J., BHATIA M., GAN O., KAPP U. and WANG J.: Assay of human stem cells by repopulation of NOD/SCID mice. Stem Cells, 15 (Suppl 1): 199-203; discussion 204-7, 1997.

5- HANEKAMP D., CLOOS J. and SCHUURHUIS G.J.: Leukemic stem cells: Identification and clinical application. Int. J. Hematol., 105: 549-557, 2017.

6- JIANG Y., XU P., YAO D., CHEN X. and DAI H.: CD33, CD96 and Death Associated Protein Kinase (DAPK) Expression Are Associated with the Survival Rate and/or Response to the Chemotherapy in the Patients with Acute Myeloid Leukemia (AML). Med Sci Monit. Apr., 9; (23): 1725-1732. doi: 10.12659/msm.900305. PMID: 28391288; PMCID: PMC5395139, 2017.

7- HOSEN N., PARK C.Y., TATSUMI N., OJI Y., SUGIYAMA H., GRAMATZKI M., KRENSKY A.M. and WEISSMAN I.L.: CD96 is a leukemic stem cell-specific marker in human acute myeloid leukemia. Proc. Natl. Acad. Sci. USA, 104: 11008-13, 2007.
8- DU W., HU Y., LU C., LI J., LIU W., HE Y., WANG P., CHENG C., HU Y.U., HUANG S., YAO J. and ZHENG J.: Cluster of differentiation 96 as a leukemia stem cellspecific marker and a factor for prognosis evaluation in leukemia. Mol. Clin. Oncol., 3: 833-838, 2015.

9- MOSTAFA N., RASHED R.A., MOHAMED W.S., et al.: Prognostic significance of progenitor cell markers CD34/CD38 expression in acute myeloid leukemia (AML) egyptian patients, 2016.

10- CHÁVEZ-GONZÁLEZ A., DORANTES-ACOSTA E., MORENO-LORENZANA D., ALVARADO-MORENO A., ARRIAGA-PIZANO L. and MAYANI H.: Expression of CD90, CD96, CD 117, and CD 123 on different hematopoietic cell populations from pediatric patients with acute myeloid leukemia. Arch. Med. Res., 45: 343-50, 2014.

11-ZHAO M., ZHU H., RAJBHANDARY S., et al.: Leukemic stem cells immunophenotype expression in patients with acute leukemia has a poor prognosis.

12- HUSSEIN S.K., EL DEEN A.A.S. and SOLIMAN N.: Significance of the expression of CD 90, 96, 117 and 123 in egyptian patients with acute myeloid leukemia, relation to prognosis and response to treatment. Electronic J. Biol., 13, 2017.

13- TERWIJN M., VAN PUTTEN W.L., KELDER A., VAN DER VELDEN V.H., BROOIMANS R.A., PABST T., MAERTENS J., BOECKX N., de GREEF G.E., VALK P.J., PREIJERS F.W., HUIJGENS P.C., DRÄGER A.M., SCHANZ U., JONGEN-LAVRECIC M., BIEMOND B.J., PASSWEG J.R., VAN GELDER M., WIJERMANS P., GRAUX C., BARGETZI M., LEGDEUR M.C., KUBALL J., de WEERDT O., CHALANDON Y., HESS U., VERDONCK L.F., GRATAMA J.W., OUSSOREN Y.J., SCHOLTEN W.J., SLOMP J., SNEL A.N., VEKEMANS M.C., LÖWENBERG B., OSSENKOPPELE G.J. and SCHUURHUIS G.J.: High prognostic impact of flow cytometric minimal residual disease detection in acute myeloid leukemia: Data from the HOVON/SAKK AML 42A study. J. Clin. Oncol., 31: 3889-97, 2013.

14- ZEIJLEMAKER W., KELDER A., OUSSORENBROCKHOFF Y.J., SCHOLTEN W.J., SNEL A.N., VELDHUIZEN D., CLOOS J., OSSENKOPPELE G.J. and SCHUURHUIS G.J.: A simple one-tube assay for immunophenotypical quantification of leukemic stem cells in acute myeloid leukemia. Leukemia, 30: 439, 2016.

15- MAJETI R. and WEISSMAN IL. Human acute myelogenous leukemia stem cells revisited: There's more than meets the eye. Cancer Cell, 19: 9-10, 2011.

16- MOHAMMAD H., WAHBA Y., GOUIDA M. and SHALTOUT A.: Cluster of Differentiation 96 in Children with Acute Leukemia: A Single Center Cohort Study. Indian J Hematol Blood Transfus. Jan., 36 (1): 178-182. doi: 10.1007/s12288-019-01145-2. Epub 2019 Jun 5. PMID: 32174696; PMCID: PMC7042468, 2020.

17- ZHANG W., SHAO Z., FU R., WANG H., LI L. and LIU H.: Expressions of CD96 and CD123 in bone marrow cells of patients with myelodysplastic syndromes. Clin. Lab., 61: 1429-34, 2015.

18-AL-FATLAWI H.H. and MUSA R.J.: Evaluation of CD96 and CD 123 in CD34+ leukemic stem cells in acute myeloid 
leukemia patients and their relation to response to induction therapy. Iraqi Journal of Hematology, 5 (2): 161, 2016.

19- YABUSHITA T., SATAKE H., MARUOKA H., MORITA M., KATOH D., SHIMOMURA Y., YOSHIOKA S., MORIMOTO T. and ISHIKAWA T.: Expression of multiple leukemic stem cell markers is associated with poor prog- nosis in de novo acute myeloid leukemia. Leuk Lymphoma, 59: 2144-2151, 2018.

20- GENTLES A.J., PLEVRITIS S.K., MAJETI R. and ALIZADEH A.A.: Association of a leukemic stem cell gene expression signature with clinical outcomes in acute myeloid leukemia. JAMA, 304: 2706-15, 2010.

\section{CD96 باعتباره علامة الخلايا الجذعية اللوكيميا

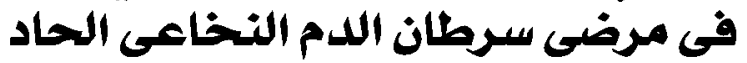 العلاقة بالعلاج الكيميائى المكثف الئف الحماد}

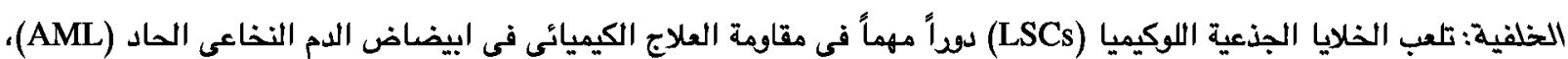

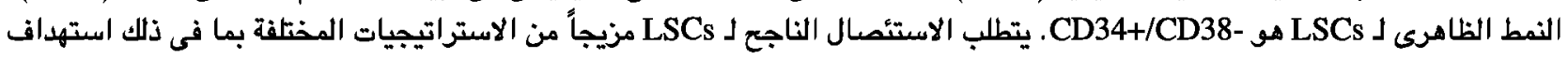
جزئيات سطح LSC المحددة.

$$
\text { هدف العمل: التحقيق فى دور CD96، كواسم للخلايا الجذعية، فى AML وعلاقته بنتائج العلاج الكيميائى. }
$$

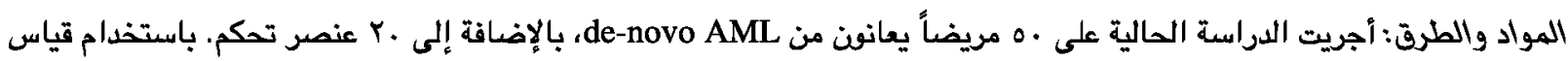

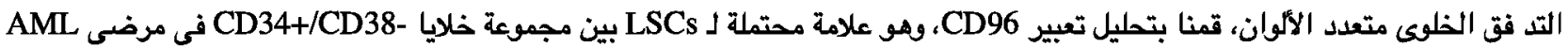

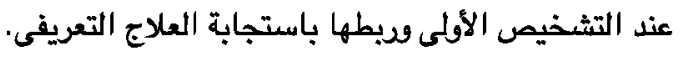

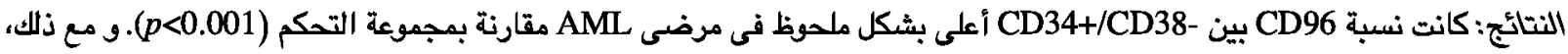

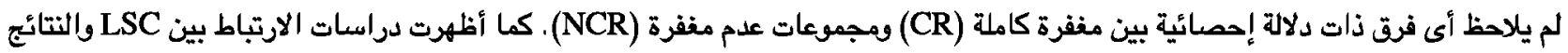
المعملية عدم وجود ارتباط معنوى ذالآن.

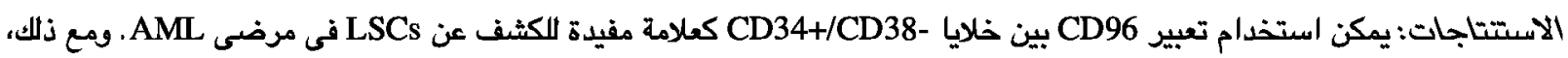

